\title{
Correction: Colonization of the tsetse fly midgut with commensal Kosakonia cowanii Zambiae inhibits trypanosome infection establishment
}

Brian L. Weiss, Michele A. Maltz, Aurélien Vigneron, Yineng Wu, Katharine S. Walter, Michelle B. O'Neill, Jingwen Wang, Serap Aksoy

The affiliation for the second author is incorrect. Michele Maltz is not affiliated with \#2 but with \# 1: Yale School of Public Health, Department of Epidemiology of Microbial Diseases, New Haven, Connecticut, United States of America.

Additionally, the current address for Michele Maltz is: Southern Connecticut State University, New Haven, Connecticut, United States of America.

\section{Reference}

1. Weiss BL, Maltz MA, Vigneron A, Wu Y, Walter KS, O'Neill MB, et al. (2019) Colonization of the tsetse fly midgut with commensal Kosakonia cowanii Zambiae inhibits trypanosome infection establishment. PLoS Pathog 15(2): e1007470. https://doi.org/10.1371/journal.ppat.1007470 PMID: 30817773

\section{G}

\section{OPEN ACCESS}

Citation: Weiss BL, Maltz MA, Vigneron A, Wu Y, Walter KS, O'Neill MB, et al. (2019) Correction: Colonization of the tsetse fly midgut with commensal Kosakonia cowanii Zambiae inhibits trypanosome infection establishment. PLoS Pathog 15(4): e1007688. https://doi.org/10.1371/journal. ppat. 1007688

Published: April 8, 2019

Copyright: ๑ 2019 Weiss et al. This is an open access article distributed under the terms of the Creative Commons Attribution License, which permits unrestricted use, distribution, and reproduction in any medium, provided the original author and source are credited. 